\section{Lo que el GPS no registra. Diálogo de saberes y mapeo colectivo del territorio ancestral indígena de San Marcos Sierras, Córdoba}

\author{
Carolina Álvarez Ávila \\ Instituto de Antropología de Córdoba \\ (IDACOR-CONICET). Museo de Antropología \\ carito_alvarez79@yahoo.com
}

Lucas Palladino

Departamento de Geografía

zpalladino@hotmail.com
Facultad de Filosofía y Humanidades. Universidad Nacional de Córdoba, Argentina.
Cultura(s) en clave de extensión universitaria / Perspectivas
RECEPCIÓN: 24/04/19

ACEPTACIÓN FINAL: 30/05/19

\section{Resumen}

Nos proponemos abordar algunas experiencias y desafíos de un proyecto de extensión universitaria en el que participamos geógrafos y antropólogos de la Universidad Nacional de Córdoba desde el año 2016. El trabajo parte de entender la extensión como una construcción colectiva de conocimiento y busca, a través del "diálogo de saberes", dar cuenta de la "pluriversidad epistemológica" implicada en las experiencias y sentidos sobre el territorio. Se pretende describir la experiencia extensionista en el marco del mapeo de sitios indígenas que abarca un relevamiento con técnicas de georrelevamiento, pero también de mapeos sociales y colaborativos mediados por el enfoque etnográfico. A partir de ello, se reflexiona sobre el aporte de este tipo de trabajos a una concepción crítica de la noción de territorio y sus herramientas de análisis y representación.

Palabras clave: territorio, cartografía oficial, mapeos colaborativos, etnografía, comunidades indígenas
What the GPS does not record. Dialogue of knowledge and collective mapping of the indigenous ancestral territory of San Marcos Sierras, Córdoba

\section{Abstract}

We propose to address some experiences and challenges of a university extension project in which geographers and anthropologists from the National University of Córdoba have participated since 2016. The work starts from understanding extension as a collective construction of knowledge and seeks through a "dialogue of knowledge" to give an account of the "epistemological pluriversity" implied in the experiences and senses about the territory. We intend to describe this experience in the process of the mapping indigenous sites that includes a survey with geo-relevation techniques but also social and collaborative mapping mediated by the ethnographic approach. From this, we reflect on the contribution of this type of work to a critical conception of territory, and its analysis and representation tools.

Keywords: territory, official cartography, collaborative mappings, ethnography, indigenous communities.
O que o GPS não registra. Diálogo de saberes e mapeamento coletivo do território ancestral indígena de San Marcos Sierras, Córdoba

\section{Resumo}

Propomos abordar algumas experiências e desafios de um projeto de extensão universitária em que geógrafos e antropólogos da Universidade Nacional de Córdoba participaram desde 2016. O trabalho parte da compreensão da extensão como construção coletiva do conhecimento e busca, por meio do "diálogo de saberes", dar conta da "pluriversidade epistemológica" implícita nas experiências e sentidos sobre o território. Pretende-se descrever a experiência de extensão no âmbito do mapeamento de sites indígenas que inclui um levantamento com técnicas de geoprocessamento, mas também mapeamento social e colaborativo mediado pela abordagem etnográfica. A partir disso, refletimos sobre a contribuição desse tipo de trabalho com as comunidades indígenas para uma concepção crítica da noção de território e suas ferramentas de análise e representação.

Palavras-chave: território, cartografia oficial, mapeamentos colaborativos, etnografia, comunidades indígenas.

Para citación de este artículo: Álvarez Ávila, C. y Palladino, L. (2019). Lo que el GPS no registra. Diálogo de saberes y mapeo colectivo del territorio ancestral indígena de San Marcos Sierras, Córdoba. +E: Revista de Extensión Universitaria, 9(10), 17-37. doi: 10.14409/extension.v9i10.Ene-Jun.8287. 


\section{Introducción}

Este artículo es un aporte resultante de las reflexiones que surgen del trabajo extensionista denominado: "Tierra de Comechingones. Reconstrucción territorial y mapeo colaborativo de sitios patrimoniales comechingones en San Marcos Sierras" (2016-2018) y "Mapeando el territorio ancestral. Memorias y lugares comechingones en San Marcos Sierras y alrededores" (2019-2020), aun en curso. Se trata de dos proyectos continuos de extensión financiados por la Secretaria de Extensión Universitaria de la Universidad Nacional de Córdoba (UNC) en el que participan docentes, egresados y estudiantes del Departamento de Geografía y Antropología y que trabaja con las comunidades comechingonas de dicha localidad serrana.

El trabajo extensionista surgió de un diálogo entre integrantes de la comunidad comechingón Sanavirón Tulián ${ }^{1}$ de San Marcos Sierras y miembros de la carrera de Geografía, cuando se invitó a Mariela Tulián (Casquicurac de la Comunidad Tulián) a conversar en torno al concepto de territorio desde la perspectiva indígena en el Seminario "Derechos humanos y territorio". ${ }^{2}$ A partir de la manifestación de la falta de políticas provinciales sobre el relevamiento de territorios indígenas en Córdoba, la situación respecto del estado de irregularidad de tierras que tradicionalmente ocupan algunas comunidades comechingonas, el intenso trabajo de los Tulián por sistematizar los documentos históricos y catastrales sobre el pasado indígena de su región, y la entonces recientemente declarada Reserva Arqueológica Quilpo por parte del gobierno provincial— al sector que comprende San Marcos y aledaños-, algunos miembros de esta comunidad extendieron la propuesta de relevar sitios considerados como patrimoniales en San Marcos Sierras ${ }^{3}$ y reunir material que fuera útil para los relevamientos territoriales propuestos en la Ley Nacional $\mathrm{N}^{\circ} 26.160 .{ }^{4}$

Estas preocupaciones hicieron que, desde el momento de confeccionar el proyecto de extensión buscáramos reflexionar sobre las metodologías participativas y extensionistas y tratáramos de poner en diálogo la perspectiva indígena, la de los enfoques etnográficos y los procesos de mapeamiento y relevamiento territorial. Así surgió la necesidad de realizar un proyecto de extensión interdisciplinar que pudiera nuclear estos ejes entre miembros de antropología y geografía, cuyos integrantes y coordinadores ya veníamos trabajando con pueblos indígenas. En estos primeros pasos buscamos que las comunidades indígenas no

1) La comunidad comechingón Sanavirón Tulián se encuentra ubicada en la localidad de San Marcos Sierras, departamento Cruz del Eje, en el noroeste provincial y es una de las primeras comunidades reconocidas por personería jurídica en Córdoba, vía INAI (Instituto Nacional de Asuntos Indígenas), en febrero de 2010. Cabe aclarar que en San Marcos Sierras es la localidad cordobesa con mayor presencia de adscriptos indígenas y comunidades comechingonas de la provincia, siendo que también existen otras comunidades comechingonas, como la Comunidad Tacu Kuntur, Tay Pichin y Timoteo Reyna.

2) Fue un seminario optativo llevado a cabo en el año 2015 en la Carrera de Geografía dictado por los docentes Sergio Chiavassa, Lucas Palladino y Carla Pedrazzani. Uno de los ejes del programa trato la relación de derechos humanos, pueblos originarios y territorio.

3) La localidad de San Marcos Sierras se encuentra situada al noroeste de la provincia de Córdoba, a $150 \mathrm{~km}$ de la capital provincial, en el departamento de Cruz del Eje. Se ubica al pie de las sierras de Cuniputo, surcada por los ríos Quilpo y San Marcos.

4) La ley declara la emergencia en materia de posesión y propiedad indígena y suspende, por cuatro años, la ejecución de sentencias y cualquier acto procesal o administrativo cuyo objeto sea el desalojo o desocupación de las tierras contempladas. Esta ley fue prorrogada en 2009 y renovada nuevamente a través de la 26.894 hasta noviembre de 2017. En 2017 se la volvió a prorrogar, en parte por los graves conflictos territoriales en curso y porque además la ley prevé relevamientos territoriales comunitarios que aún se adeudan en todo el país. 
sean objeto de nuestros diálogos y prácticas extensionistas sino interlocutores y sujetos de co-construcción de conocimiento. Recuperando la perspectiva de Sousa Santos (2009), entendimos que nuestro trabajo extensionista debe partir de un "diálogo de saberes" que colectivamente construye conocimiento sobre el territorio indígena, sus pautas y prácticas (políticas) para concebirlo y habitarlo.

En este artículo presentamos, en primer lugar, la descripción del proceso de trabajo de campo extensionista llevado a cabo a partir de 2016. En segundo lugar, la reflexión desde el concepto de territorio como categoría moderna y la complicidad de la cartografía oficial en su representación. En tercer lugar, luego de retomar el aporte de la cartografía social y los mapeos colectivos, destacamos nuestra experiencia con las comunidades indígenas de San Marcos Sierras en el registro de su territorio ancestral.

\section{La propuesta del proyecto}

El proyecto consiste en la realización de relevamientos territoriales y mapeos colaborativos entre miembros de los Departamentos de Antropología y Geografía de la Universidad Nacional de Córdoba y las mismas comunidades. Nuestra metodología consiste en relevar y registrar los "sentidos nativos" (Guber, 2001) sobre el territorio, lo cual comprende un abanico de técnicas cualitativas, como las entrevistas en profundidad, la observación participante y la realización de registros de campo. Ahora bien, estos relevamientos devienen de una primera socialización y negociación colectiva, entre miembros extensionistas y comechingones. Es decir, de un listado de recorridos y sitios que ellos consideran prioritarios, hemos ido revisando y negociando cuándo y cómo registrarlos. Durante estos recorridos y sitios, que son caminados colectivamente, realizamos registros y tomas de notas de las categorías y discusiones emergentes. Por otro lado, como se explicará en los próximos apartados, parte del trabajo se enfoca, primero, en la realización de mapeos colectivos y cartografía social y, luego, del relevamiento mediante GPS de los "puntos y líneas" que son recorridos y registrados como aspectos cruciales del territorio indígena.

La primera etapa del proyecto consistió en salidas grupales entre miembros del equipo de extensión y de las mencionadas comunidades. Al inicio, los viajes fueron mensuales y luego se hicieron bimensuales. Después de cada viaje y trabajo de campo en San Marcos Sierras y alrededores se sistematizó la información recabada: desgrabación de información registrada en audios y en videos, confección de fichas y organización de mapas con información georreferenciada, fotografías y registros de recorridos. El procesamiento de esta información siguió los términos de confidencialidad pactados con los miembros de las comunidades. En la medida en que las salidas grupales comprendieron una cantidad importante de sitios relevados, y que algunos de ellos nos fueron descritos como "históricos", 5 se inició una pesquisa más profunda en archivos y catastrales para obtener más información, recurriendo concretamente al Archivo Histórico Provincial y a la Dirección General de Catastro (sección "archivos"). Esta información también está siendo digitalizada y clasificada. De hecho, digitalizamos el expediente completo de un importante juicio que Francisco Tulián, de la comu- 
nidad del pueblo de San Jacinto, realizó a la Corona española durante los años 1803 a 1809, y que en la actualidad es utilizado por la comunidad como evidencia de jurisprudencia de la ocupación histórica comunitaria. ${ }^{6}$

Posteriormente, transitamos la segunda etapa del proyecto, que implicó la reflexión y confección de ejes transversales que permitieron hacer los talleres bajo consignas focalizadas. Es decir, en esta segunda etapa se llevaron a cabo los primeros talleres colectivos de cartografía social que describiremos.

En la actualidad, estamos trabajando en una producción cartográfica dinámica e integral que busca presentar parte de lo realizado a través de un mapa interactivo digital sobre el territorio de las comunidades comechingón.

\section{Descentrar la producción cartográfica sobre el territorio: de la cartografía oficial a los mapeos colectivos y el enfoque etnográfico}

Respecto de la metodología de los mapeos colectivos, colaborativos y la cartografía social, hemos sistematizado lecturas y discusiones que tienen que ver con las discusiones en las geografías latinoamericanas (Ascerald, 2013) e indígenas (Martínez Berrios et al., 2015; Offen, 2009) pero también del aporte de colectivos u organizaciones independientes del campo académico, como Iconoclasistas (Asler y Risler, 2013). En líneas generales, la cartografía social ha puesto, en tono de denuncia, la complicidad de la cartografía oficial como herramienta de poder, especialmente su vinculación con los proyectos imperiales y en la legitimación de los nacientes Estados nacionales modernos (Ares y Risler, 2013; Ascerald, 2013; Harley, 2005). Se entiende que el mapa ha sido una herramienta que privilegió el orden dominante y estructuró una epistemología de orden racionalista y euclidiana. Así, como otros dispositivos -el censo, el museo (parafraseando a Anderson, 1993)—, el mapa operó como una tecnología de gobierno (Foucault, 2006; Elden, 2010) que contribuyó a la construcción de los territorios estatales (Lois, 2014). Cabe entender que el mismo concepto de territorio ha estado impregnado de análisis elitistas, tal como muestra Raffestin (1993) al notar que la geografía positivista-regionalista (como disciplina encargada de representar el territorio mediante mapas) privilegió siempre un análisis de lo "concebido" en detrimento de lo "vivido". En esta línea, la cartografía ofició como elemento privilegiado de representación del territorio moderno.

Como decíamos, la "cartografía social", en tono de denuncia, ha acompañado la crítica a la construcción territorial de la mano de los Estados modernos como también a que el mapa se haya instituido como herramienta de "el" cartógrafo. ${ }^{7}$ Por el contrario, se propone a la cartografía como una herramienta teórico-metodológica que busca relevar, interpretar y trabajar con otros colectivos y agentes sociales como sujetos de conocimiento. De esta manera, permite atender experiencias, sentidos y significaciones que tienen que ver con el territorio y los procesos de (des) y (re)territorialización vividos por dichos colectivos y sujetos. Así, los mapeos colaborativos ofrecen la posibilidad de volcar sobre un plano los sentidos, valoriza-

6) Vale la pena aclarar que este expediente fue hallado por miembros de la comunidad Tulián y se nos confió su digitalización como parte importante de los archivos que ayudan a repensar la historia del territorio ancestral que ocupan. 7) Acompañamos la descripción sexista que apunta Gilliam Rose (1993) al mostrar la interseccionalidad de género, raza y clase que operan en las prácticas de producción de conocimiento geográfico. 
ciones y experiencias propias de las representaciones diferenciales del espacio que tienen dichos actores sociales. Los mapeos ofrecen alternativas factibles a los procesos de reconstrucción de la geografía y de la historia de las comunidades silenciadas o invisibilizadas.

Cabe destacar que la producción cartográfica en nuestra zona de trabajo acompaña estos supuestos sobre la cartografía. Observamos que en la localidad de San Marcos Sierras los mapas catastrales jugaron un lugar privilegiado en la demarcación de tierras modernas y liberales. Como se advierte en la página 1 del expediente de juicio de Francisco Tulián, 1809, la comunidad Tulián reconoce como un antecedente importante la demarcación de tierras comprendida en el juicio que la misma (como Pueblo de San Jacinto o San Marcos) llevó adelante contra la gobernación del Tucumán en el período 1803-1809 y cuyo resultado fue que se les reconociera su territorio (el epicentro estaba próximo a la localidad de San Marcos Sierras y abarcaba un territorio más extenso que este).

Esta es información sumamente valiosa que permite a las narrativas orales "poner en evidencia" la territorialidad histórica de la comunidad. Ahora bien, una vez consolidado el Estado-nación (y luego de aprobada la Constitución Nacional de 1853), la cartografía (a través de creación del Departamento Topográfico provincial) pasó a jugar un papel clave en el estriamiento del territorio (Deleuze y Guattari, 1994), representando planos de propiedades con un conjunto de íconos euclidianos (puntos, líneas y polígonos). Por otro lado, en el siglo XIX, el entonces Pueblo de Indios de San Jacinto ${ }^{8}$ pasó a ser considerado como "comunidad indígena de San Marcos", y esta dividida, para finales del siglo XIX, partiéndose el territorio indígena en una serie de polígonos que denotan la propiedad privada de las tierras.

La división cartográfica de estos Pueblos de Indios y su nueva denominación como "comunidades indígenas" son conocidas por los miembros de la comunidad Tulián no solo porque están presentes en trabajos historiográficos (Tell, 2019, 2012; Reyna, 2018), ${ }^{9}$ sino también porque forman parte de las memorias orales familiares que circulan entre los miembros de la comunidad y entre otras familias de la zona. Como sostiene Mariela Tulián en cuanto a este reconocimiento provincial temprano de "comunidad": "fue un concepto tramposo, porque el Estado nos reconoce para desconocernos". ${ }^{10}$

De lo observado hasta aquí notamos cómo se hace patente trabajar con las perspectivas, memorias locales de las comunidades indígenas de San Marcos, en el contexto de sus propias perspectivas sobre el/su territorio e historia en la medida en que, parafraseando a Spivak (1987), estas perspectivas fueron subalternizadas, invisibilizadas e inaudibilizadas (Bidaseca

8) Los llamados Pueblos de Indios fueron reducciones indígenas que existieron durante la colonización española en todo el continente americano. Fueron fomentados por las autoridades españolas en la segunda mitad del siglo XVI, a partir de la Real Cédula de 1545. Se los ideó para realizar un cobro más eficiente de los tributos; para aumentar el control y facilitar el proyecto de aculturación de la población sometida mediante la prédica cristiana; y para asegurarse la concentración y disponibilidad de mano de obra.

9) Por ejemplo, el trabajo de Sonia Tell (2012) sobre el pueblo de Indios de San Jacinto. Además, la autora ha mantenido numerosos diálogos con la comunidad y el equipo extensionista triangulando las fuentes orales y documentales sobre el pasado colonial y republicano de la región. Otro abordaje que destacamos es el de Pablo Reyna, adscripto comechingón de la comunidad Timoteo Reyna, quien ha realizado un trabajo sobre el proceso de desarticulación territorial de la comunidad de indios de San Marcos en el siglo XIX.

10) El mismo planteo es compartido por Boixadós (2006) y por Castro Olañeta y Tell (2016) al mostrar que la emergencia de la categoría de comunidad indígena se solapa con las políticas de desarticulación de comunidades iniciadas en la segunda mitad del siglo XIX. 
et al., 2011) por los dispositivos estatales y la misma historiografía local. Aquí subyace nuestro interés por la reconstrucción, por encontrar aquello que quedó sin ser representado o valorado en las lógicas y prácticas de las mensuras y/o delimitaciones territoriales implicadas dentro de las diferentes cartografías oficiales y, sobre todo, por aportar a la (re)construcción colectiva de los sentidos indígenas sobre territorio y comunidad. En esta línea consideramos que trabajar con mapeos puede contribuir a "reafirmar su geografía y su historia, negadas o silenciadas por los Estados nacionales, y reivindicar sus derechos sobre la tierra", y que el trabajo con cartografía social puede "permitir a pueblos y comunidades indígenas, reforzar su identidad y su cultura tanto como las estructuras sociales y políticas propias" (Hirt, 2009:4).

Todas estas perspectivas subalternizadas, invisibilizadas e inaudibilizadas nos llevaron -casi obligatoriamente- a tejer diálogos con la antropología social y el enfoque etnográfico. Como en cualquier proyecto extensionista, siempre las preguntas por las metodología y determinadas técnicas son de exigente preocupación. Y dados los objetivos del proyecto, entendimos que la etnografía era ineludible no solo por ofrecer un cúmulo de técnicas sino, en especial, por abarcar una manera de mirar y problematizar el mundo; como sostiene Guber, por consistir en "un enfoque". Entendemos así a la etnografía como "una concepción y práctica de conocimiento que busca comprender los fenómenos sociales desde la perspectiva de sus miembros" (Guber, 2001:11-12). Esto corresponde a elaborar una conclusión interpretativa y explicativa que no se da por una generalización directa a partir del caso observado, sino que proviene de la articulación teórica del investigador y su contacto prolongado con el grupo de estudio. En otras palabras, el "enfoque etnográfico" permite acceder a la perspectiva de los actores y de lo "no documentado" de la vida social (Guber, 2004).

En nuestro proyecto, entonces, la opción de este enfoque fue nodal para que estos otros sentidos, valorizaciones y experiencias sobre el territorio pudieran ser registrados y articulados al trabajo cartográfico en curso. Esto implicó la concreción de entrevistas abiertas o semidirigidas y el registro de información mediante la observación participante y no participante, intentando atender a nuestra presencia en el lugar y las diferentes percepciones, dificultades y limitaciones que, como docentes, graduados y estudiantes de la UNC, íbamos experimentando en los sucesivos viajes y recorridos.

\section{La reserva, el sitio y el territorio: entre visiones nativas, gubernamentales y disciplinares}

Es importante destacar que empezamos trazando un itinerario de sitios y recorridos a partir de tener en cuenta el territorio que comprende la Reserva Arqueológica Quilpo, creada en 2015 mediante la Ley provincial $N^{\circ} 10.308$, impulsada por el trabajo de la Agencia Córdoba Cultura y su área de Patrimonio Cultural. La reserva se entiende como

"un área que alberga un conjunto de sitios arqueológicos que por el valor social y científico que se le asigna a sus restos culturales o fósiles, es destinada a salvaguardar la cultura material, en especial si hubiera riesgo de destrucción o deterioro por la actividad antrópica y con el fin de preservar determinadas pautas culturales propias y cuya relación armónica con el medio sea necesario garantizar". (Ley provincial № 10.308, 21 de octubre de 2015) 
Así, el criterio de delimitación fue asignado por los técnicos de Patrimonio Cultural, quienes lograron recorrer parte de los sitios incluidos en la Reserva pero no su totalidad.

Cabe destacar que la figura de la reserva se propone como objetivo la protección, preservación, estudio, revalorización y difusión de los yacimientos y bienes arqueológicos (art. 2 de la misma ley), entendidos estos como cosas muebles e inmuebles, ruinas, edificaciones, pinturas, dibujos, grabados, pictografías, petroglifos, morteros, cualquier tipo de obra de arte, entre otros. Si bien esta definición contempla los aspectos del patrimonio cultural e intangible, las mismas comunidades indígenas destacaban que allí se comprenden sitios que no abarcan la memoria vivida y vívida y sus propias concepciones y experiencias sobre estos lugares. Además, aunque el trabajo realizado por el gobierno provincial y sus técnicos es valorado por las comunidades, estas se preocuparon porque muchos de los sitios y lugares no habían sido debidamente registrados y nos solicitaron relevarlos en el marco del trabajo extensionista. De hecho, a partir de conseguir un GPS financiado por el mismo gobierno pudieron georreferenciar algunos espacios considerados de importancia cultural, económica y espiritual, pero no les resultó suficiente y consideraron que esto debía formar parte del trabajo conjunto. El poder incorporar otra serie de "sitios no registrados" por "patrimonio" (designación metonímica de los agentes que trabajan en la mencionada oficina gubernamental) y poder preservarlos dentro de la figura de Reserva Quilpo fue uno de los primeros sentidos y preocupaciones que registramos al inicio del trabajo. Por otra parte, el trabajo con los agentes gubernamentales tampoco pudo profundizar en la historia y sentido de cada sitio, lo que sería toda una dimensión para investigar en futuros trabajos. Por lo tanto, como dijo una interlocutora en San Marcos, "es necesario llenar de contenido los sitios".

Desde allí, nuestro equipo trazó un cronograma de trabajo sobre la base de los sitios a relevar en el marco del territorio indígena ancestral presente en los límites de la Reserva Arqueológica Quilpo.

Figura 1. Polígono de la Reserva Arqueológica Quilpo.

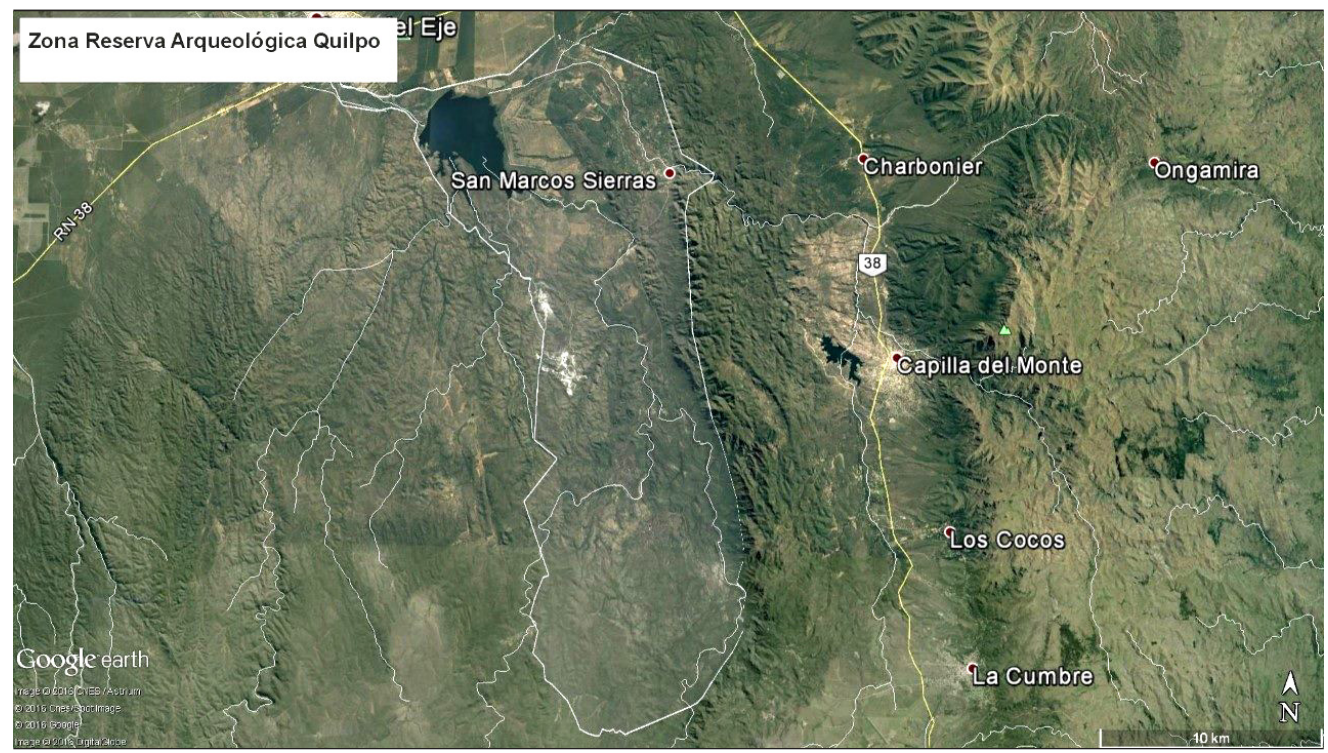

Fuente: Cartografía realizada por miembros del proyecto extensionista, Oscar Vives y Federico Saldaño, 2018. 
Vale la pena resaltar, ya habiendo transcurrido dos años del inicio del proyecto, que nuestro propio trabajo comenzó con una serie de mapeos y de recorridos que de alguna manera estaban más cuantificando que cualificando esos sitios. Como se observa en la Figura 2, que es un primer esbozo sobre los sitios recorridos, nosotros mismos acompañábamos un registro que apuntaba más a la "materialidad" de los sitios que a su profundidad histórica y complejidad cultural.

Mediante nuestro dispositivo de GPS relevábamos sitios como puntos localizados en el plano (con coordenadas), y al consultarles sobre si se consideraba "sitio" el lugar relevado, muchas veces no había respuestas explícitas, en el sentido de que el propio camino, con su complejidad de historias, vivencias, "hallazgos" arqueológicos, o la integridad de flora y fauna, parecían tener "mayor" importancia en la definición de lo registrable para y en los mapas (ver Figuras 1 y 2).

En efecto, parte de la demanda de las comunidades comechingonas era relevar y registrar sitios, recorridos y lugares que hacen a su territorio ancestral y que nos han llevado a relevar también árboles, plantas, arbustos, diferentes especies de animales, aspectos de la flora y fauna que surgen en cada lugar al que fuimos. En nuestros recorridos, los lugares que registramos son señalados como hábitat de pumas, osos mieleros, diversas especies de pájaros, entre otros. Además, comenzó a ser muy importante en nuestra experiencia la identificación de huertas naturales, entendidas como los lugares donde crece todo tipo de plantas y hierbas para consumo alimentario y medicinal. En cada viaje efectuado, nuestros interlocutores nos demandaron que estas huertas naturales fueran también registradas y relevadas. Mientras el registro sucedía, nos iban explicando el nombre o denominación de las plantas y hierbas y nos contaban los usos actuales y de antaño de cada especie encontrada. Se mencionaron también algunos sitios específicos, donde se nos solicitaba pedir permiso y "entrar con respeto, para no ofender a los espíritus que allí viven". La presencia de estos espíritus y los ancestros explica en parte que allí se realicen varios rituales y ceremonias, tanto en el pasado como en el presente. Al iniciar, por ejemplo, nuestro recorrido por el camino de Yastay, el cual nos llevó finalmente a la Casa del Uturunco, Mariela nos contó sobre la presencia de las pencas y los espíritus que allí habitan:

"En él habitan guerreros y espíritus que van abriendo el camino hacia la casa del Uturunco. Estos guerreros son las Pencas del territorio, ellos son testigos del paso del tiempo, son quienes hacen de portal y nos dejan pasar o no a la dimensión espiritual. Desde el mojón hasta la casa del Uturunco encontramos estas Pencas que, en varias oportunidades - al menos en invierno que es la época seca— sobresalen sobre la vegetación arbustiva. (...) Las pencas son, para nosotros, los testigos del paso del tiempo, los guerreros que - con una nueva forma - custodian el lugar, los que nos observan y deciden si nos abren o no los caminos, las puertas espirituales. (...) No cualquiera está preparado para tomar los mensajes y saber leerlos. No cualquiera está preparado en el corazón". (Mariela Tulián, agosto de 2016)

Parte de lo que expresa Mariela es compartido por los comuneros, para quienes en los sitios también habitan "espíritus" o "ancestros". En este sentido, nuevos desafíos se colocaron en nuestro registro "visual" mediado por el relevamiento. Cabe aclarar que la presencia de la dimensión espiritual en los pueblos indígenas viene siendo cada vez más atendida y estudia- 
Figura 2. Relevando puntos, líneas, polígonos.

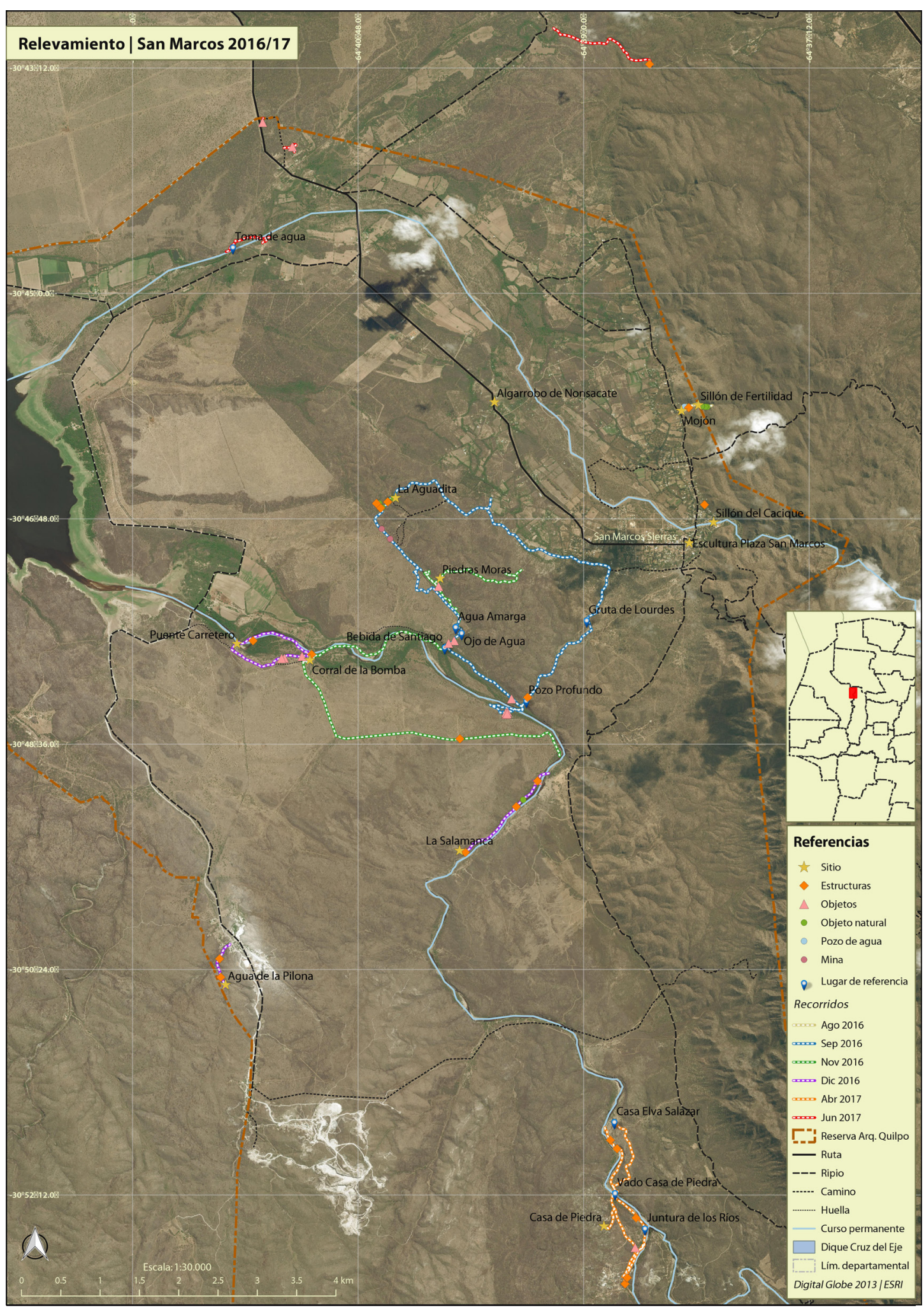

Fuente: Cartografía realizada por miembros del proyecto extensionista, Oscar Vives y Federico Saldaño, 2018. 
da, siempre con el desafío de poder darle la relevancia precisa, sin reducirla a definiciones vacías que sirvan para un enciclopedismo academicista. Así, esta definición dialoga con una visión relacional del concepto territorio, que comprende las articulaciones de lugares (más que la definición de un sitio), el movimiento, la presencia de seres, entidades, humanos y no humanos (Escobar, 2012, 2015). Esta visión relacional se vincula a una concepción epistemológica y ontológica (Blaser, 2014) ${ }^{11}$ en tensión con las epistemologías modernas y racionalistas, que concebían al territorio como un plano material, ámbito o zona demarcada o delimitada, de propiedad. Blaser pone en discusión estos elementos cuando muestra que en los "conflictos ontológicos" median tensiones entre la política racional (agenciada en prácticas gubernamentales y "científicas") y las mismas perspectivas relacionales inscriptas en la agencia indígena. ${ }^{12}$

En esta dirección, nos interesa destacar que tuvimos que fortalecer la formación y la discusión de categorías entre los miembros del equipo. Forman parte de las discusiones que venimos sosteniendo cómo dar entidad y visibilidad a esta dimensión espiritual indígena en nuestro trabajo de mapeo colaborativo que pueda servir a proteger los sitios, ampliar su definición y contribuir a seguir analizando críticamente los usos estratégicos de nociones como patrimonio, reserva, sitios, áreas buffer, ${ }^{13}$ lugar, entre otras. Es decir que para darle cabida y relevar las visiones nativas en toda su complejidad y profundidad es imprescindible que cuestionemos y volvamos relevantes nuestras propias visiones y aquellas que han sido apropiadas de discursos y prácticas gubernamentales (sitio, reserva arqueológica, patrimonio, etcétera).

Ahora bien, esto no implica menospreciar nuestros dispositivos de mapeo. Nos referimos a la georreferenciación de puntos y sitios mediante técnicas de relevamiento geográfico (GPS y GIS) que, como mostramos, son ineludiblemente relevantes para las comunidades. De hecho, tal como se ha analizado en estudios de relevamiento territorial de norpatagonia (Cañuqueo, 2015; Arias, 2010), las mismas cartografías son usadas por las comunidades indígenas como herramienta de reivindicación territorial, en algunos casos con un uso "contrahegemónico" (Arias, 2010). Pero en esta dirección, la demanda de las comunidades de "llenar de contenido" ciertos sitios y lugares muy importantes para ellos nos obliga a atender no solo a estos modos hegemónicos de aprehender y relevar el territorio, sino también a buscar otros modos de registrar y comprender como válido y epistemológicamente relevante aquello que ha permanecido oculto o invisibilizado en los relatos y registros oficiales. Esto fue $-\mathrm{y}$ continúa siendo- efectivamente un desafío para el equipo extensionista, cuyos miembros provenimos

11) Para una profundización sobre el recorrido conceptual y análisis indígena sugerimos el texto de Álvarez Ávila (2014 y 2017).

12) No desconocemos que esta operatoria de análisis en base a enfoques de la ontología política puede implicar menospreciar que ambos mundos están constituyéndose en las prácticas. Es decir, para evitar el riesgo de esencializar la visión nativa/indígena y de negar la "mirada moderna", confluimos con parte de los mencionados autores en que estas perspectivas se configuran co-constituyéndose en la indigeneidad. Asimismo, cabe complejizar estas perspectivas como existentes en el marco de relaciones históricas, sociales y de poder.

13) El buffer suele definirse como el polígono que encierra el "área de influencia" resultante de una determinada distancia en torno a un punto, línea o polígono. Se utiliza mucho para delimitar zonas de influencia para explotaciones mineras, por ejemplo. 
de diversas formaciones académicas y que debimos compartir - y seguimos haciéndolosaberes y experiencias para potenciar nuestro proyecto.

\section{Lo que el GPS no registra: del relevamiento de sitios a los mapeos colectivos}

¿Cómo dar cuenta de esta diversidad de experiencias y sentidos sobre los sitios y el territorio indígena? Una de las cuestiones a tratar fue el recorte del registro de recorridos y su debido tratamiento interpretativo-etnográfico para que nuestro equipo pudiera comprender, en su integridad, la importancia de estos lugares desde el punto de vista nativo. En este sentido, de más de media centena de sitios relevados durante más de dos años de visitas, escogimos tres que, debido a su reiterada mención en las entrevistas en San Marcos, consideramos que era importante trabajar en una primera etapa.

Así, recuperamos la metodología de los mapeos colectivos y colaborativos para, primero, diagnosticar los aspectos del territorio que podían ser trabajados en la construcción de la representación cartográfica final ${ }^{14} \mathrm{y}$, luego, profundizar en la multidimensionalidad de sentidos que las comunidades Tulián y Tay Pichin construyen en torno a ellos.

En esta línea un lugar escogido, de mutuo acuerdo, fue Casa de Piedra. Se trata de un "sitio arqueológico" reconocido por el gobierno provincial (mediante el relevamiento que realizó Patrimonio Cultural como parte de la Reserva Arqueológica Quilpo); también por la Municipalidad de San Marcos Sierras, que en su página web lo muestra como uno de los destinos o "paseos turísticos" y lo describe como: "Monumento Arqueológico que se presenta de manera imponente por su magnitud y por historia, es una gran piedra con cavidades de formación natural y en algunos sitios modificado por los aborígenes". ${ }^{15}$

También es un reconocido paraje de la arqueología local, sitio de excavaciones de arqueólogos y aficionados. ${ }^{16}$

A pesar de estos diversos reconocimientos de Casa de Piedra, el lugar es objeto de diversas disputas por parte de las comunidades indígenas, para quienes es parte del territorio ancestral de la comunidad, sobre el cual enfatizan su importancia histórica y espiritual. Las comunidades han denunciado diversas problemáticas allí presentes. En primer lugar, el impacto de las excavaciones arqueológicas (muchas de ellas ilegales) y el guaqueo o extracción ilegal y comercio de piezas. En segundo lugar, el impacto ambiental del turismo new age ${ }^{17}$ debido a la consideración del lugar como "centro energético y chamánico" (la extracción de yuyos o hierbas consideradas medicinales alrededor, la realización de

14) Representación digital que se encuentra en proceso de elaboración.

15) Fuente: http://sanmarcossierras.gov.ar/web/?page_id=28 (consultado el 4 de junio de 2019).

16) Por un lado, se reconoce el trabajo de Bornancini (2013) en el relevamiento de Cattáneo, Costa e Izeta (2013). Estos han colocado a Casa de Piedra como sitio arqueológico dada la presencia de arte rupestre y objetos líticos. Por el otro, un aficionado local, Juan Carlos Sansó, ha realizado numerosas excavaciones adjudicando al lugar adjetivos místicos, y ha publicado un libro, El día que las piedras hablaron, sobre su experiencia en el sitio arqueológico: "Esta es la historia de un libro que yo no quería escribir, porque tengo que contar los datos de un descubrimiento arqueológico que me sucedió hace muchos años. Este hallazgo lo hice en una caverna en las nacientes del rio Quilpo en medio de las sierras Cordobesas" (Sansó, 2017:s/p).

17) Seguimos a Flores y Oviedo (2017), quienes bajo la denominación de turismo new age destacan que tienen lugar diversas prácticas: turismo esotérico, ufoturismo, terapias alternativas, la turistificación de rituales y espiritualidades de pueblos originarios, el ecoturismo, el turismo místico, entre otras. 
fogones al interior de la caverna, que carbonizan las pictografías, la modificación de piedras con objeto de pernocte y el consecuente cambio de dirección del agua de lluvia que erosiona el suelo). ${ }^{18}$

De esta manera lo expresan miembros de las comunidades:

"(S): Además el tema de la riqueza, todos lo vieron, la cantidad de medicina que hay en todo el lugar, ¿no? Entonces vos te centras aquí y aquí está todo. Así que alguien que quiere ganarse unos mangos, viene, se instala aquí y vende el curso. Lo venden online también, viste, y esto es de acá. Y se instalaron acá adentro y chau, ¿no?

(M): Hay por lo menos tres empresas o tres cosas así montadas alrededor de la espiritualidad de Casa de Piedra". (Notas de campo, junio de 2017)

A este respecto, las comunidades consideran fundamental recuperar la memoria oral, en la medida en que para algunas familias ese lugar fue transmitido como un "lugar de reuniones", también "escuela" u "hospital", especialmente asociado a la medicina de la comunidad:

"Mariela: Impactante. Este lugar era una escuela y a la vez también como una clínica como un hospital. Acá vivía quien hacía medicina (...) Y él, a veces, bajaba, iba a las comunidades, al pueblo, a visitar familiares enfermos para llevar medicina, y cuando estaban muy enfermos los traía acá unos días y los curaba porque para nosotros la enfermedad tiene una parte espiritual muy importante. Para trabajar lo espiritual, es este lugar (...). Este es el lugar de reuniones para nosotros donde vive el espíritu ese ahí adentro, ahí el lugar donde habita digamos como el ser espiritual que domina al sitio. Es a la vez también un divisadero... salimos por ahí y encontramos una piedra, digamos, donde se hacen ceremonias. $Y$ más allá hay un montón más de aleros muy similares a este y hay un cementerio también muy cerquita de acá...". (Notas de campo, junio de 2017)

Como se advierte en el relato de Mariela, además de los sentidos vinculados a la medicina, el sitio puede entenderse por su complejidad en relación con la transmisión y la espiritualidad. Asimismo, es importante por la presencia de otros objetos, como piedras, aleros, cementerios y por las prácticas ceremoniales que allí se hacen.

Como efecto de esta diversidad de disputas sobre el lugar y de la necesidad de su protección, las comunidades iniciaron un proceso de negociación con el actual propietario del campo, quien al comienzo se dispuso a "ceder en comodato" el terreno. De hecho, a lo largo del año 2017 se realizaron algunas reuniones de negociación e incluso una mensura a final del mismo año ${ }^{19}$ con el objetivo de intentar lograr un control sobre el lugar y mitigar los daños

18) Destacamos que Casa de Piedra es apenas uno de muchos sitios que son objeto de denuncia por parte de las comunidades. Las mismas nos expresan que, cada vez con mayor urgencia, precisan defender el territorio de varios atropellos acontecidos. En las últimas décadas, la localidad se ha vuelto un destino de creciente interés turístico y el territorio se ve cada vez más explotado para dar lugar a hoteles, hostels, albergues, restaurantes y negocios de varios rubros, no solo en la zona central de la localidad sino también en las afueras y en los alrededores de San Marcos Sierras. Los miembros de las comunidades locales viven en estado de alerta permanente por los loteos que se anuncian y se concretan sin los permisos adecuados y en situaciones legales dudosas. Parte de nuestro trabajo, de hecho, fue acompañar algunos procesos de denuncias y reclamos, escribiendo al respecto para difundir estas problemáticas y ofreciendo herramientas de georreferenciación para apoyar sus demandas (ver, AA. VV., 2017).

19) Mensura que pretendió trabajar con la zona de reconocimiento para el comodato de las comunidades indígenas. Esta mensura fue puesta en tensión en la medida que su relevamiento solo contemplaba el sendero de inicio al sitio y 
e impacto que preocupan a las comunidades. La problemática de Casa de Piedra nos permitió comprender lo complejo de algunos conflictos territoriales, donde no solo el Estado es el interlocutor a quien se demanda, sino también los dueños, que son vecinos de la zona, con quienes las comunidades intentan entablar diálogos y construir alianzas en pos de defender lo que consideran importante.

En este contexto, nuestro mapeo necesitaba de una instancia colectiva de discusión para repasar y jerarquizar junto a las comunidades lo relevado hasta este momento. A finales de 2018 desarrollamos una serie de talleres que buscaron volcar en un plano (compuesto por un mapa base de la Reserva arqueológica, tal como se observa en la Figura 4, y una serie de "hojas de calcar" yuxtapuestas). Al iniciar el trabajo, y luego de explicar en qué consistía el taller de mapeo, decidimos iniciar con Casa de Piedra.

Al trabajar sobre este sitio se hicieron presentes, por un lado, problemáticas actuales vinculadas al lugar (como sostuvimos, la propiedad privada, la explotación minera, el turismo espiritual) y, por el otro, expresiones acerca de la importancia espiritual y memoria oral de y para las comunidades. Mariela proponía sobre el mapeo:

"Mariela: Habría que contar todo en el mapa. (...) Es hora de desmitificar. Estaría bueno dividir por un lado lo que se puede constatar y contraponerlo con nuestra memoria oral. Por un lado, la historia con fotos y testimonios y, por otro, la memoria oral. Dice [se refiere a un aficionado a la arqueología e historia local] que los comechingones teníamos ese nombre porque comíamos tierra. Trabajar con fotos en juego con la memoria oral. Historiadores desconocen la memoria oral como válida, y (...) es el dueño del museo. Disputamos con él la historia de Casa de Piedra. Este sitio es un territorio de disputa. Sansó dice que empezó a ir porque lo llamaban. El Ser que el desenterró se comunicaba con él todo el tiempo y le contó toda la historia del pueblo. Místicamente él escribió toda nuestra historia.

Más adelante podríamos ir recuperando los espíritus de los sitios y representarlos con animales. Nosotros tenemos una estética bien nuestra." (Registro del Taller de mapeo, octubre de 2018)

En línea con la preocupación de los Tulián y algunos miembros de la comunidad Tay Pichin, se sostenía que era importante destacar los "usos y abusos" en el lugar, expresando así tanto la dimensión cultural y espiritual como la necesidad de denunciar los "abusos".

Al escuchar estos sentidos sobre el lugar y sobre las prácticas en el mismo, hicimos un plano compuesto por dos hojas de calcar superpuestas y se decidió colocar en una los "abusos" y en la otra "los usos".

En la Figura 3 podemos observar la realización provisoria de la capa de "usos" sobre Casa de Piedra así como algunos dibujos y la clasificación de los elementos importantes para las comunidades. En primer lugar, en el centro, se dispara una serie de flechas que indican: los elementos espirituales (hierbas medicinales, chelco o iguana), luego la presencia del cementerio, parideras, morteros y conanas; ${ }^{20}$ el denominado "pigmeo", que es una representación 
pictográfica presente al interior de la cueva, y finalmente la referencia al lugar como "sitio transmisión de saberes ancestrales". Estos elementos fueron luego ordenados en colores con una dimensión de significado de cada uno. El violeta, "lo intangible"; el rojo para los "sitios históricos"; y naranja para "lo comunitario" o la "fuerza colectiva".

Figura 3. Capa de "usos" en un mapa provisorio y colectivo de Casa de Piedra.

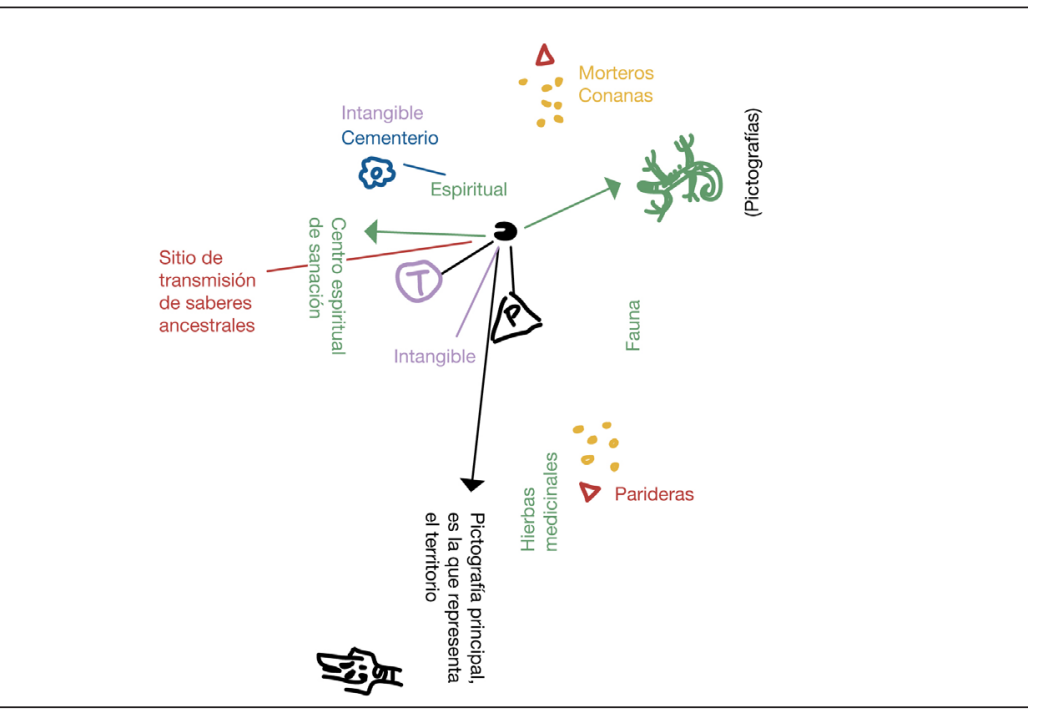

Fuente: en base a fotografía de los autores, octubre de 2018.

Otro lugar mapeado a lo largo de los talleres fue el sitio del Mojón, también conocido como "Camino de Yastay". Se trata de uno de los primeros sitios relevados por nuestro equipo extensionista. Al igual que Casa de Piedra, ya había sido relevado como "arqueológico" en la base de datos de la Reserva Arqueológica Quilpo de la provincia de Córdoba. También la Municipalidad de San Marcos Sierras lo reconoce como un "lugar de importancia histórica" y lo describe como mogote o "mojón que dividía el territorio de Comechingones al Sur y Sanavirones al Norte. Camino a El Rincón". No obstante, las comunidades lo referencian no solo describiendo la materialidad del mojón y su fijación como punto sino también apelando al carácter inmaterial, espiritual y por la presencia circular y areal de elementos que lo definen (de hecho, el lugar es referenciado por nuestros interlocutores como "el mojón", "el camino de Yastay" o "la casa del Uturunco"). Desde la perspectiva de nuestros interlocutores comechingones, la concepción de sitio de la agencia estatal que había relevado la zona era y es limitada en tanto solo se registraron como puntos definidos por la coordenada cartesiana, y es importante destacar la memoria de los abuelos, que hablan de espíritus guerreros hoy presentes en las pencas. Así, desde perspectiva indígena, los sitios incluyen un área más amplia y a la vez móvil, como la comprendida por el camino de Yastay.

"El sitio es grande, amplio; imponente, y no puede ser desmantelado. En él habitan guerreros y espíritus que van abriendo el camino hacia la casa del Uturunco. Estos guerreros son las Pencas (cactus altos y alargados) del territorio, ellos son testigos del paso del tiempo, son quienes hacen de portal y nos dejan pasar o no a la dimensión espiritual. Desde el 
mojón hasta la casa del Uturunco encontramos estas Pencas, que en varias oportunidades -al menos en invierno que es la época seca- sobresalen sobre la vegetación arbustiva. Dicen los abuelos que hubo grandes festividades y también luchas; eso fue haciendo que quedaran algunos restos, en distintas formas. Por eso hay guerreros que cayeron luchando de manera desprendida, muy sentida, quedaron en el territorio de otra forma. Las pencas son, para nosotros, los testigos del paso del tiempo, los guerreros que - con una nueva forma- custodian el lugar, los que nos observan y deciden si nos abren o no los caminos, las puertas espirituales. "Ellos nos marcan el camino, el camino que seguimos es el que nos marcan ellos, los testigos del paso del tiempo". (Registro de campo, agosto de 2016)

Destacan el sitio por la presencia de espíritus en el monte nativo, y lo consideran masculino porque allí habita el espíritu de Yastay. Abundan piedras, morteros, hierbas medicinales, y hay ciertos espacios reservados para ceremonias.

El relevamiento del equipo extensionista consistió, entonces, no solo en registrar la descripción y relatos sobre dos sitios puntuales (el Mojón y la casa del Uturunco) sino también en experimentar el camino del modo en que lo propuso nuestra interlocutora, registrando - con nuestros propios cuerpos - el recorrido que lleva desde un punto al otro. "El camino nos cambia, implica tanto esfuerzo... Para la comunidad, el camino es importante en sí, es espiritual, y no es solo para nosotros. Es un sitio de equilibrio" (Mariela Tulián, agosto de 2016). De hecho, las mujeres que frecuentemente recorren el camino sostuvieron: "Hay que estar preparados para atravesar este camino, en caso contrario, parte de nuestros espíritus van quedando encerrados aquí...”.

Ese recorrido fue realizado, en su mayoría, por mujeres del equipo extensionista, puesto que es un lugar concebido, como dijimos, como masculino. A partir de esta experiencia y de allí en adelante, nuestro trabajo de campo no solo incluyó una descripción a través de nuestra participación observada en los lugares y sitios, sino que constituyó una forma de habitar y engranarse (Ingold, 2002) en el territorio. Por medio del movimiento, nuestros cuerpos se articularon con los sitios, recorridos y entidades no humanas en una imbricación sensible con el monte.

Al momento de hacer el mapeo colectivo del Mojón y Yastay nació, primero, la necesidad de dibujar el movimiento y el camino y de dar lugar a los elementos intangibles del paisaje. En el siguiente mapa puede observarse, por ejemplo, el énfasis en la representación de área circular del territorio y de una cantidad de elementos significativos que exceden al sitio Mojón (ver Figura 4).

Se puede ver en la imagen que el Mojón es apenas una referencia dentro del gran mapa del sitio, que comprende una serie heterogénea de puntos con sus respectivos significados y sentidos para quienes mapearon el lugar. Se observan la presencia de elementos materiales (pencas, casas pozo, pirca), el camino (trazado en violeta, color elegido para representar "lo intangible"), y se representa el área como "triángulo".

En los talleres se nos volvió evidente el papel otorgado al camino. En esta línea, cabe destacar que las experiencias vinculadas a las sendas, huellas y caminos, son narradas por varios miembros de las comunidades como parte constitutiva de sus vivencias en el territorio. Por ejemplo, Juan Carlos Tulián nos invitó a recorrer grandes extensiones de kilómetros por sendas apenas abiertas por cabras, y parte del sentido que nuestro interlocutor nos brindó 
tenía que ver con caminar lugares que estaban asociados a su trabajo (cuidado de cabras), al involucramiento que ofrecía en términos de hallazgo de monte nativo pero también de lugares que, desde las memorias orales, hablan de la historia comechingón de la zona.

De esta manera, la identificación con la realización de prácticas agrícolo-ganaderas, como la recolección de frutos y hierbas y el esquilado de animales, se inscribe como una dimensión relevante para nuestros interlocutores y contribuye a dar sentido al territorio desde las experiencias del involucramiento y la movilidad. ${ }^{21} \mathrm{Y}$ si bien estas últimas aparecen en sus relatos y memorias, ellos nos instaron a recorrer y experimentar algunas de esas huellas y senderos y a que eso formara parte del trabajo colaborativo.

Figura 4. Primer mapa provisorio y colectivo del Mojón, Uturunco y Yastay.

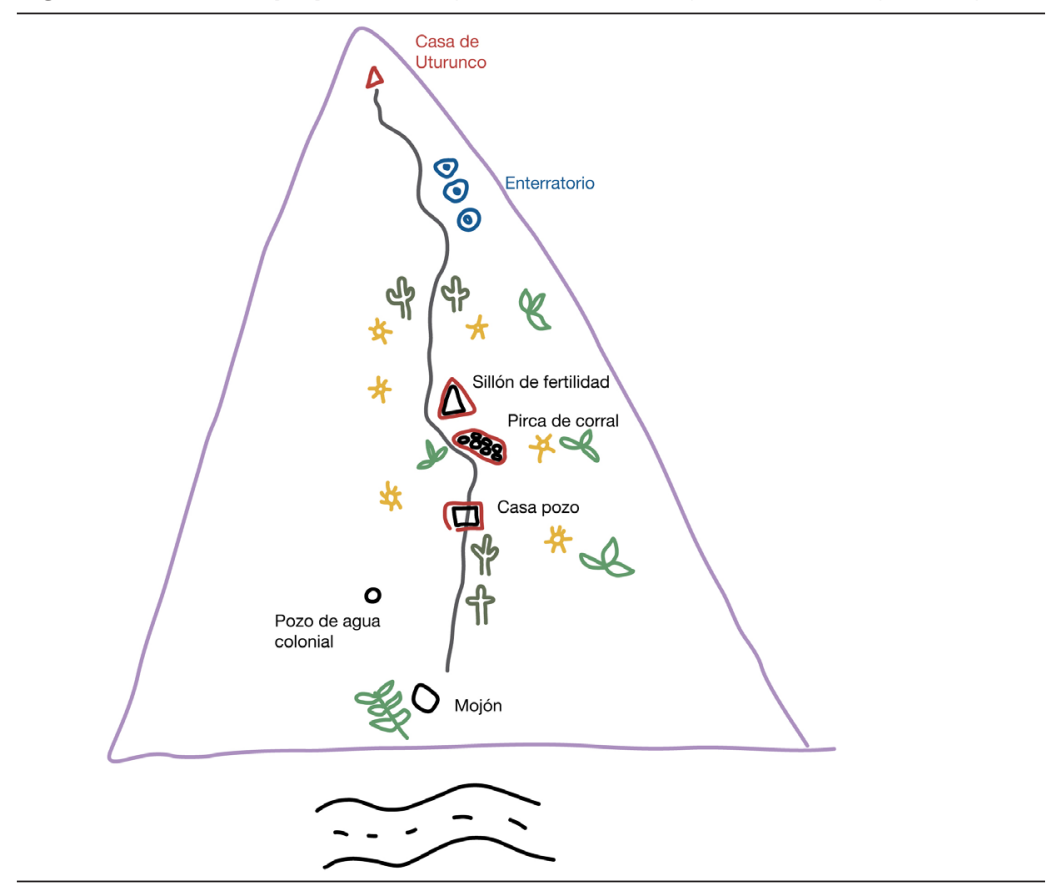

Fuente: en base a fotografía de los autores, octubre de 2018.

\section{A modo de cierre}

En este trabajo hemos apuntado a recorrer, en parte, la construcción colectiva y colaborativa de conocimiento sobre el territorio, en el marco de un proyecto extensionista en curso, con adscriptos comechingones en San Marcos Sierras y sus alrededores. Sostuvimos que el "diálogo de saberes" es trascendental para la construcción colectiva de conocimiento y que ello también deviene en la propuesta de dar cuenta lo que autores del grupo modernidad-colonialidad-decolonialidad han propuesto como la "pluriversidad epistemológica" implicada, fundamentalmente, en marcar la relación colonial de los saberes locales, históricamente si-

21) La dicotomía entre fijación y movilidad es, en efecto, otra dimensión que nos interpela y que hemos abordado sucintamente en otro trabajo (Palladino y Álvarez Ávila, 2018). 
lenciados e invisibilizados, y, a su vez, en su visibilización y comprensión epistemológica actual. Planteamos que, en efecto, el trabajo extensionista trabaja para reconstruir colectivamente estos conocimientos con las mismas comunidades comechingonas en Córdoba, en especial mediado por la dimensión territorial.

En este sentido, nuestro trabajo hizo hincapié en la cuestión del territorio. En primer lugar, sucintamente apuntamos ${ }^{22}$ que la formación del territorio moderno y su representación mediante una serie de cartografías en tanto dispositivo de poder pudieron contribuir a la invisibilización y desarticulación de las poblaciones originarias. A través de la triangulación con material bibliográfico consultado (Harley, 2005; Lois, 2014), sostuvimos que la cartografía se dispone como herramienta de representación moderna, y que subyace una epistemología racionalista, anclada en una geometría euclidiana. En segundo lugar, y como objeto de crítica de dicha producción cartográfica y territorial, nuestro equipo buscó activar metodologías colectivas, colaborativas (Ares y Risler, 2013; Acselrad, 2013) y constructivistas para atender a cómo los colectivos comechingones de San Marcos perciben, experimentan, habitan y representan el territorio.

Esta complejidad está contemplada en el diálogo del enfoque etnográfico (Guber, 2001), las técnicas de relevamiento territorial y los mapeos colectivos. Mencionamos que, en un principio, nuestro equipo se centró en el relevamiento mediante GPS y su representación de GIS. Desde la emergencia de aspectos relacionales en el sentido ontológico sobre el territorio (Escobar, 2015) fueron mayores las preocupaciones por poner en la mesa la realización de mapeos colectivos y poder registrar los complejos mundos de los sentidos, experiencias y prácticas espaciales de dichos colectivos. En esta línea, este trabajo reflexionó sobre una primera experiencia de mapeo y el derivado de tensiones con nuestros propios habitus disciplinares (teóricos y metodológicos).

Primero, sostenemos que la preocupación sobre el territorio es de carácter relacional. Esta cuestión no puede ser ubicada en un mapa únicamente a través de líneas, puntos y polígonos, o bien por la bidimensionalidad del plano. La perspectiva ontológica en la que el territorio es concebido como la imbricación de espíritus, personas, humanos-no humanos, supera la concepción areal inscripta en las categorías modernas e invita a pensar los flujos, el movimiento, la agencia de otras entidades. Si articulamos con las nociones posestructuralistas sobre el término (Haesbaert, 2004), consideramos que es útil continuar profundizando en esta línea, puesto que es una discusión cara al concepto de territorio, que la misma praxis indígena (y otras subalternidades) está poniendo en discusión. ${ }^{23}$ Además, cuando decimos

22) En el sentido de que todavía queda al equipo atender a la complejidad de las fuentes históricas producidas a nivel regional.

23) Es importante mencionar que muchos trabajos vienen discutiendo cómo dar cuenta de nociones y sentidos sobre el territorio que subviertan las definiciones tradicionales. Se trata de una discusión emergente en cuanto a la genealogía conceptual, y que la misma agencia indígena, en tanto categoría de la práctica, está poniendo en cuestión. Es esta agencia la que nos ofrece la tensión epistemológica de la representación territorial, la fijeza de los mapas y de los límites. Existen, por ejemplo, trabajos que analizan la trashumancia de las comunidades indígenas (Arias, 2010; Gasco, Durán et al. 2015). Otros estudios abordan cómo estos desplazamientos recrean lugares y territorios de las comunidades, siendo el territorio definido más allá de la noción hegemónica de "comunidad" (Barros, 2000; Cladera, 2013). Finalmente, también son un gran aporte los trabajos que analizan los procesos de des y reterritorialización, como los de Gordillo (2010a y b), que contrastan las experiencias de movimiento de grupos indígenas con los relatos hegemónicos que inscriben nociones de fijación y estabilidad en sus geografías. 
relacional, apuntamos a hacer visible nuestro propio engranaje (Ingold, 2002) y experiencia sensible, como modo en que se imbrica a los sentidos y prácticas nativas.

Segundo, derivado de lo anteriormente expresado, el territorio se define por un conjunto de sitios que a su vez contemplan algo más que su materialidad y fijación. Mostramos la concepción de la Agencia Córdoba Cultura y su área de Patrimonio, condensada en la creación de Reserva Arqueológica y las correspondientes marcaciones derivadas. El descontento de las comunidades por no abarcar "el contenido" debía ser encarado por nuestro trabajo colectivo. Aquí la noción de sitio contempla lo inmaterial, espiritual, ceremonial, las historias contadas por los abuelos. El sitio puede ser también un lugar con presencia viva de espíritus, y su definición corresponde a la relación con otros lugares (en un territorio contiguo reticular).

Tercero, y como ya sugerimos, estos sitios son aprehensibles mediante otro registro sensorial: el nuestro. Nuestros interlocutores, sus trayectorias, memorias y prácticas nos vienen interpelando en nuestro propio hacer cuando, por ejemplo, nos demandan "poner el cuerpo", "pedir permiso", "entrar con respeto", oler una hierba, tocarla, agacharnos, saltar, mojarnos en el río, entre otras acciones. Aprender a mirar, e incluso sentir el territorio, apelando a nuestro sentido y valorando nuestras sensaciones, continúa siendo un desafío y aprendizaje permanentes.

Así, consideramos que nuestro trabajo extensionista apuesta a una construcción colaborativa y colectiva no solo porque cruza saberes a modo de diálogos, sino además porque el territorio nos invita a ser vivido y concebido de la manera que proponen las mismas comunidades comechingones. El territorio dialoga con las perspectivas simbólico-culturales (Haesbaert, 2004). En la medida en que la representación y la identidad o lo vivido juegan un papel fundamental, también "el lugar" emerge no solo como "una cosa en el mundo" sino como "una manera de entender el mundo" (Creswell, 2004:11). Cuando lo sensorial y el cuerpo emergen como dispositivos de aprehensión de los sitios, el territorio igualmente lo hace en un sentido fenomenológico. El lugar puede ser entendido como "espacio corporeizado" (Serje, 2008) y ello se asemeja a lo que algunas líneas posfenomenológicas (Ingold, 2002, entre otros) vienen trabajando y que atienden a la materialidad y agencia del paisaje, al entramado de sentidos que participan en su construcción por fuera del dispositivo moderno de la vista y de su espectador como sujeto dislocado del mundo.

En un texto de reflexión etnográfica sobre un proceso de mapeo en la Sierra Nevada colombiana, el mencionado Serje reflexionaba sobre lo no representado en "la línea negra", ${ }^{24}$ el mapa topográfico, la línea trazada verticalmente por la cartografía técnica y oficial de las agencias gubernamentales que delimitaba dicho territorio. Según la autora, estos actos de delimitación cartesianos no contemplaban el entramado de historias, relatos y sentidos, la confluencia de voces que crean conexiones con el entorno, y así el proceso de configuración de los lugares como construcciones múltiples, culturales y sociales. En la línea de Serje,

24) Según los pueblos indígenas que habitan la Sierra Nevada, está rodeada por una línea negra invisible que abarca los lugares sagrados de sus ancestros y demarca su territorio. La línea negra se relaciona con un conjunto de padres y madres espirituales que conforman estructuras de gobierno propio, materializado geográficamente en forma de cerros, rocas, cuerpos de agua, entre otros. Cada uno de estos padres se ubica en espacios sagrados que conforman líneas, círculos y espirales invisibles. 
nuestro trabajo apuntó a contemplar el carácter vivido y vívido de estos territorios, pensando en nuestros dispositivos, como lo que el GPS "no registra".

Este escrito muestra algunas primeras reflexiones y esboza posibles emergencias epistemológicas y ontológicas que surgen a partir de la riqueza del "diálogo de saberes" territoriales - pero no únicamente - con comunidades comechingonas de San Marcos Sierras. Es, finalmente, una invitación al intercambio con nuestros colegas, lectores, autores y editores de esta revista.

\section{Referencias bibliográficas}

AA.VV. (Equipo de Extensión “Tierra de Comechingones") (2017). Entre preservar y explotar: loteos y desmontes en la Reserva Arqueológica Quilpo. Recuperado de: https://latinta.com.ar/2017/07/ preservar-explotar-loteos-desmontes-la-reserva-arqueologica-quilpo/

Acselrad, H. (2013). Cartografia social, terra e território. Rio de Janeiro: IPPUR/UFRJ.

Álvarez Ávila, C. (2014). Ser mapuche en(tre) mundanizaciones: sentidos y tensiones de pertenencia y devenir en una comunidad mapuche neuquina. Tesis inédita del Doctorado en Ciencias Antropológicas de la Universidad Nacional de Córdoba.

(2017). Levantar viento en la rogativa. Señales, equivocaciones y comunicaciones entre humanos y fuerzas de la naturaleza. Antípoda. Revista de Antropología y Arqueología, (29), 149-173. doi: https://dx.doi. org/10.7440/antipoda29.2017.07

Álvarez Ávila, C. y Palladino, L. (2018) Experiencias y diálogos en el mapeo colectivo de territorios comechingones en San Marcos Sierras y alrededores. E + E: estudios de Extensión en Humanidades, 5(6), 96-111.

Ares, P. y Risler, J. (2013). Manual de mapeo colectivo: recursos cartográficos críticos para procesos territoriales de creación colaborativa. Buenos Aires: Tinta Limón.

Arias, S. (2010). Mapeo autónomo y defensivo en la Zonal Pewence. En 4tas Jornadas de Historia de la Patagonia. Universidad Nacional de Comahue, Bariloche.

Anderson, B. (1993). Comunidades imaginadas. Reflexiones sobre el origen y la difusión del nacionalismo. México: Fondo de Cultura Económica.

Barros, C. (2000). Reflexiones sobre la relación entre lugar e identidad. Documents d'Anàlisi Geogràfica, (30), 81-94.

Bidaseca, K.; Gigena, A.; Guerrero, L.; Millán, F. y Quintana, M. (2011). Dispositivos miméticos y efectos de identidad. Ensayo de una interpretación crítica sobre las personerías jurídicas y las comunidades originarias. En Bidaseca, K. (Coord.). Signos de la identidad indígena. Emergencias identitarias en el límite del tiempo histórico (pp. 153-168). Buenos Aires: SB.

Blaser, M. (2014). Reflexiones sobre la Ontología Política de los Conflictos Medioambientales. Newfoundland: Memorial University.

Boixadós, M.C. (2006). Las representaciones cartográficas de la Ciudad de Córdoba. Entre 1870 a 1930. En Lois, C. (Coord.). Imágenes y lenguajes cartográficos en las representaciones del espacio y del tiempo: I simposio iberoamericano de historia de la cartografía (pp. 17-26). Buenos Aires: Universidad de Buenos Aires. Bornancini, C. (2013). Cerro Colorado. El chamán, el cóndor y el jaguar. Arte rupestre, patrimonio cultural y conservación. Córdoba: Imprenta de la UNC.

Cañuqueo, L. (2015). El territorio relevado, el territorio disputado. Apuntes sobre la implementación de Ley nacional 26.160 en Río Negro, Argentina. Revista de Geografía Norte Grande, (62), 11-28. 
Castro Olañeta, I. y Tell, S. (2016). Los pueblos de indios de Córdoba del Tucumán y el pacto colonial. Siglos XVII a XIX. Revista del Museo de Antropología, 9(2), 209-220.

Cattáneo, R.; Costa, T.E. e Izeta, A. (2013). El patrimonio arqueológico de los espacios rurales de la provincia de Córdoba. Córdoba: Universidad Nacional de Córdoba.

Cresswell, T. (2004). Place: a Short Introduction. London: Blackwell.

Elden, S. (2010). Land, terrain, territory. En Elden, S. Progress in Human Geography. Durham University, UK. Traducción interna: Avila Emanuel, Llorens Santiago, Palladino Lucas. Cátedra de Epistemología de la Geografía. Departamento de Geografía. Ffyh, UNC)

Escobar, A. (2012). Cultura y diferencia: la ontología política del campo de cultura y desarrollo. Walekeru, (2). Recuperado de: http://edu-library.com/es/walekeru

(2015). Territorios de diferencia: la ontología política de los derechos al territorio. Cuadernos de Antropología Social, (41), 25-38.

Flores, F. y Oviedo, M. (2017). Imaginarios turísticos, construcción de atractivos y new age. El caso de San Marcos Sierras (Argentina). Estudios y Perspectivas en Turismo, 26, 493-508.

Foucault, M. (2006). Seguridad, Territorio, Población. Curso en el Collége de France (1977-1978). Buenos Aires. Fondo de Cultura Económica.

Gasco, A.; Durán, V.; Piazze, L.; Giardina, M., y Campos, G. (2015). Veranadas sin frontera. Etnografía de pastores en el centro-oeste argentino. Revista del Museo de Antropología, 8(2), 133-146.

Gordillo, G. (2010a). Lugares de diablos. Tensiones del espacio y la memoria. Buenos Aires: Prometeo.

— (2010b). Deseando otro lugar: reterritorializaciones guaraníes. En Gordillo, G. y Hirsch, S. (Comps.). Movilizaciones indígenas e identidades en disputa en la Argentina. Buenos Aires: La Crujía.

Guber, R. (2001). La etnografía: método, campo y reflexividad. Buenos Aires: Norma. (2004). El salvaje metropolitano. Buenos Aires: Paidós.

Haesbaert, R. (2004). O mito da Desterritorializaçao. Do "fim dos territórios" à multiterritorialidade. Rio de Janeiro: Bertrand.

Harley, J.B. (2005). La nueva naturaleza de los mapas: ensayos sobre la historia de la cartografía. México: Fondo de Cultura Económica.

Hirt, I. (2009). Cartographie et peuples autochtones: géographie postcoloniale ou néocoloniale? L'exemple de Chodoy lof mapu au Chili. Mappemonde, 4(96). Recuperado de: http://mappemonde.mgm.fr/actualites/ hirt_mois.html

Ingold, T. (2002). The temporality of the landscape. In Ingold, T. The Perception of the. Environment Essays on livelihood, dwelling and skill (pp. 189-207). London: Routledge. Traducción S. Llorens. Seminario: Enfoques culturales de Paisaje en Geografía. Departamento de Geografía. Ffyh, UNC.

Lois, C. (2014). Mapas para la nación: episodios en la historia de la cartografía argentina. Buenos Aires: Biblos. Martínez Berrios, N.; Sepúlveda, B. y Palomino Schalscha, M. (2015). La cuestión territorial indígena en América Latina: algunas perspectivas desde Chile y Argentina. Revista de Geografía Norte Grande, (62), 5-9.

Offen, K. (2009). O mapeas o te mapean: mapeo indígena y negro en América Latina. Tabula Rasa, 10, 163-189.

Palladino, L. Movilizando sentidos de pertenencia comechingones. Una etnografía de los procesos de comunalización y territorialización en las comunidades del Pueblo de La Toma y Ticas (Provincia de Córdoba). Tesis inédita del Doctorado en Ciencias Antropológicas de la Universidad Nacional de Córdoba.

Palladino, L. y Tulián, M. (2015). Revivir el territorio sagrado: a los pazos de Francisco Tulián. Cardinalis, Revista electrónica de geografía, 3(5), 232-255. 
Palladino, L. y Álvarez Ávila, C. (2018). Desafíos del mapeo colaborativo como trabajo extensionista. Una experiencia con comunidades comechingonas en San Marcos Sierras. E+E: Estudios de Extensión en Humanidades, 5(6), 96-111.

Raffestin, C. (1993). Por uma geografia do poder. São Paulo: Ática.

Reyna, P. (2018). La desarticulación territorial de la comunidad de indios de San Marcos hacia fines del siglo XIX. Tesis inédita de grado de la Licenciatura en Historia de la Universidad Católica de Córdoba.

Rose, G. (1993). Feminism and geography. The limits of geographic knowledge. Minessota: University of Minessota Press.

Sansó, J. (2017). El día que las piedras hablaron. La gran historia de los comechingones jamás contada. Córdoba: Editorial de la Muncipalidad de Córdoba.

Serje, M. (2008). La invención de la Sierra Nevada. Antípoda, 197-229.

Sousa Santos, B. de (2009). Una Epistemología del Sur. La reinvención del conocimiento y la emancipación social. Buenos Aires: Siglo XXI Editores y CLACSO.

Spivack, G. (1987). In Other Worlds. Essays in Cultural Politics. New York: Methuen.

Tell, S. (2012). Conflictos por tierras en los "pueblos de indios" de Córdoba. El pueblo de San Marcos entre fines del siglo XVII y principios del siglo XIX. Andes, 23(1), 71-103. Recuperado de: http://www.scielo.org.ar/ scielo.php?script=sci_arttext\&pid=S1668-80902012000100003

(2019). ¿Una república de 'indios puros’? Comunidad, autoctonía y legitimdad. Córdoba, Gobernación del Tucumán, siglo XVIII. Memoria Americana. Cuadernos de etnohistoria, 27(1), 126-148.

Tell, S. y Olañeta I. (2011). El registro y la historia de los pueblos de indios de Córdoba entre los siglos XVI y XIX. Revista del Museo de Antropología, 4, 235-248.

Tulián, M. (2016). Zoncoipacha: Desde el corazón del territorio. El legado de Francisco Tulián. Córdoba: CICCUS. Walsh, C. (2007). ¿Son posibles unas ciencias sociales/culturales otras? Reflexiones en torno a las epistemologías decoloniales. Nómadas, 26, 102-113.

\section{Fuentes}

Boletín Oficial (2006). Ley Nacional № 26160. Buenos Aires, 29 de noviembre.

Boletín Oficial (2013). Ley Nacional № 26.894. Ley № 26160. Prórroga. Buenos Aires, 21 de octubre.

Boletín Oficial (2017). Ley Nacional № 27.400. Prórroga. Ley № 26160. Buenos Aires, 23 de noviembre.

Ley provincial 10.308, 21 de octubre de 2015. Recuperado de: http://web2.cba.gov.ar/web/leyes.nsf/85a69a561f9ea43d03257234006a8594/aec312f80f858be103257eec007362c9?OpenDocument (consultado el 9 de junio de 2019). 